ISSN: 0210-7287

DOI: https://doi.org/10.14201/1616202111141162

\title{
HENRY JAMES Y LA FICCIÓN-TRICKSTER
}

\section{Henry James and the Trickster-Fiction}

\author{
José Manuel CuEsTA ABAD \\ Universidad Autónoma de Madrid \\ jm.cuesta@uam.es
}

Recibido: 1/06/2020; Aceptado: 15/10/2020; Publicado: 31/12/2021

Ref. Bibl. JOSÉ MANUEL CUESTA ABAD. HENRY JAMES Y LA FICCIÓN-TRICKSTER. 1616: Anuario de Literatura Comparada, 11 (2021), 141-162

RESUMEN: Este artículo propone una aproximación al concepto de ficcióntrickster a través de la lectura de los relatos y nouvelles de Henry James, con especial atención a los paralelismos entre "La figura en la alfombra" y "La bestia en la jungla». En estas novelas la interpretación de un secreto se convierte en elemento principal de la estructura narrativa (argumental y discursiva), de modo que la incertidumbre hermenéutica causa finalmente un efecto de indecidibilidad en relación con el secreto que motiva la intriga. Desde esta perspectiva, la ficción-trickster no constituye un modo nuevo o especial de relato, sino una explicitación radical de algunos trucos o procedimientos de la literatura fantástica, y cifra al mismo tiempo una manifestación singular de la crisis de la mímesis característica de ciertas tendencias de la literatura moderna.

Palabras clave: arte de la ficción; Henry James; literatura del secreto; truco narrativo; relato hermético; interpretación e indecidibilidad.

ABSTRACT: This article develops an approach to the concept of 'tricksterfiction' through reading of Henry James's short stories and nouvelles, with particular attention to the parallel between "The Figure in the Carpet» and "The Beast in the Jungle». In these novels the interpretation of secrecy becomes a central element in the narrative structure, since hermeneutic uncertainty causes 
an effect of undecidability in connection with the secret that motivates the emplotment of fictional events. From this point of view, the 'trickster-fiction' is not a new or special mode of narrative, but a radical explicitation of the tricks and procedures of fantastic literature, and it also constitutes a singular form of the mimetic crisis that characterizes some tendencies of modern literature.

Key words: art of fiction; Henry James; literature of secrecy; narrative trick; hermetic story; interpretation and undecidability.

1.

Todo parece obedecer a un malentendido tras cuyo aspecto fortuito quizá se esconda la secreta maniobra de una trama. Todo se refiere aquí a la argucia que complica los sucesos de una historia, al argumento de un relato $y$, en definitiva, al arte de la ficción: un arte que requiere cierta habilidad para la intriga. En un pasaje notable de "The Art of Fiction" (1884), Henry James llama execution a esa habilidad particular del narrador para enredar eficazmente los múltiples hilos de una historia. La ejecución, advierte, es para el autor lo más personal, y para el lector lo que da la verdadera medida de la obra, es la posibilidad virtualmente ilimitada que tiene el novelista de experimentar tanteando desarrollos del tema latentes e imprevistos, descubriendo procedimientos inéditos de construcción narrativa, trenzando sutilmente las hebras de la acción y los puntos de vista hasta formar una urdimbre donde el lector quede atrapado como en una telaraña inevitable: "Su manera es su secreto, no necesariamente un secreto deliberado. Pues él no puede desvelarlo en términos generales aunque quiera: no podría enseñárselo a otros ${ }^{1}$. "His manner is his secret». Manera significa el modo de proceder mediante el cual un escritor trabaja la ejecución narrativa y cifra en ella, al mismo tiempo, el secreto de su arte. Ningún autor tiene en su mano desvelar de una vez por todas el artificio singular que encierra su estilo de ejecución y, sin embargo, por una paradoja indisociable del trabajo mismo de escritura, tal manera es justo aquello que constituye su originalidad como narrador y que puede proporcionar al lector la medida de la excelencia o la grandeza de su arte. Arte de la ficción, conviene no olvidarlo, cuya clave permanece oculta entre los hilos narrativos que la ejecución enmaraña de un modo único y acaso inextricable.

1. Las traducciones, salvo otra indicación, son del autor del trabajo (JMCA). 
De lo que se va a tratar es de un mutismo irónico, de una extraña reticencia que ningún escritor puede evitar. Silencio imperativo del que Northrop Frye parte en las primeras páginas de su Anatomy of Criticism (1957) cuando sostiene que «el axioma de la crítica debe ser no que el poeta no sabe de lo que está hablando, sino que no puede hablar de lo que sabe». Puesto que no hay modo de que el escritor descubra o enseñe a los demás el quid de su manera particular de hacer las cosas, la teoría que él mismo pueda extraer de la reflexión sobre su arte tendrá probablemente especial interés -concede Frye-, pero no especial autoridad. Este corolario resulta del todo aplicable al conjunto de los textos teóricos y autointerpretativos de Henry James. Son, todos ellos, del mayor interés, en la medida en que no solo giran inercialmente alrededor de la manera de ejecución de su narrativa, sino que además la reflejan al mostrar de ella, ante todo, su dimensión no desvelable, es decir, no menos arcana para el propio autor que para el hipotético lector. De un ensayo a otro, en "The Art of Fiction" y en los dieciocho prefacios escritos para la gran edición de Nueva York que debía reunir sus novelas (1907-1909) -publicados más tarde por Richard P. Blackmur bajo el imponente título de The Art of the Novel (1934)-, o en muchas de las cavilaciones por momentos confesionales de los Notebooks, cuyas páginas registran puntual y cuidadosamente, año tras año, los esbozos y proyectos narrativos que se le iban ocurriendo, el novelista se empeña en exhibir su ansiedad por anticipar el plan ideativo y dominar cuanto sea posible el proceso de invención, y se entrega a interminables disquisiciones sobre los vínculos entre situation y execution.

Hay situaciones que se nos antojan de por sí más interesantes que otras. Unos niños que parecen vivir atemorizados por el asedio fantasmal de un funesto pasado (The Turn of the Screw) o unos padres que encuentran azarosamente un marido ideal, dispuesto al compromiso, para su única hija hace tiempo fallecida ("Maud-Evelyn») son tesituras a primera vista más curiosas, y seguramente más atrayentes, que la de un individuo de mediana edad a quien ronda la obsesión de haber fracasado como escritor ("The Middle Years») o la de una joven y rica heredera que debe exponerse a unas cuantas vicisitudes morales y sentimentales en su algo accidentada evolución personal (The Portrait of a Lady). Sin embargo, el interés narrativo de una situación no reside tanto en su cariz más o menos extraño, chocante o inaudito, cuanto en la transformación literaria de cualquier acontecimiento en un suceso intrigante. Lo que Henry James llama situation tiene una estructura muy similar a la del fait-divers diseccionado por Roland Barthes: la de un hecho vivido cabalmente como si fuera un signo cuyo significado es incierto y puede que indescifrable. El encuentro aleatorio, la coincidencia sospechosa, el azar repetido son algunas de 
las marcas discontinuas que delimitan la zona de sombra trazada por esa desconcertante casualidad fatal característica del suceso. Fatalidad inteligente -pero ininteligible-», señala con su acostumbrada agudeza Barthes. Digamos que una situación solo se vuelve literariamente intrigante en la medida en que su apariencia contingente sea convertida por la forma de ejecución narrativa en portadora de una significación oculta largamente mantenida en vilo. Por ser inseparable de una situación más o menos dramática, la ejecución remite siempre de algún modo a la experiencia vital; por ser inseparable de una determinada manera de ejecución, la situación reconduce igualmente al proceso de escritura y al arte de la ficción. De ahí la importancia que James otorga al tema y al problema acuciante de sus virtuales desarrollos (developments, los denomina en el «Prefacio a Roderick Hudson»), pues el asunto mismo debe constituirse en figura situacional del secreto constructivo encriptado en la manera de ejecución. Ahora bien, ¿en qué consiste tal secreto?

«El secreto del relato jamesiano es precisamente la existencia esencial de un secreto, de algo no nombrado, de una fuerza ausente y superpotente que pone en marcha toda la maquinaria de la ficción", destacaba Tzvetan Todorov en un artículo temprano ("Le sécret du récit", 1971), donde recogía también la tesis de Introduction à la littérature fantastique según la cual el James de The Turn of the Screw representa un paradigma de la hésitation o vacilación interpretativa entre lo real y lo maravilloso que define a los ambiguos universos de la literatura fantástica. Cuando -y mientras- duda de si los horribles fantasmas son producto de la imaginación delirante de los personajes o acaso tienen realidad efectiva en el mundo de ficción, el lector permanece inmerso en la atmósfera equívoca e inquietante de una narración fantástica, suspendido como un funambulista dubitativo sobre la línea inestable que separa el realismo racional de la fabulación sobrenatural (Todorov, 1970; Ceserani, 1996). Todorov admite de buen grado que tal incertidumbre interpretativa implica poner en cuestión los límites «irreductibles» entre lo real y lo irreal. Pero este cuestionamiento depende por completo de una lectura referencial del texto literario fundada en un conocimiento apriorístico y, en definitiva, incuestionable de la clara y distinta franja ontológica que separa la experiencia real de la ficcional. Resolver la vacilación es de hecho salir no ya de lo fantástico, sino del espacio literario mismo. Es hacer del secreto que guarda la obra de ficción un sentido descifrado antes o después por medio de un saber monolítico, sin resquicios, inapelablemente realista, escéptico, raciocéntrico. Sin embargo, el trabajo de la literatura en cuanto ficción no consiste solo en representar universos imaginarios, unas veces verosímiles y otras decididamente fabulosos, sino también en explorar esa experiencia límite, inmanente al lenguaje, que da 
lugar en la escritura a la continua ósmosis de realidad y fantasía. El asunto primordial -y el factor constructivo- del relato literario es en cada caso la mímesis del fantasma, figura de una hibridación proteica y tornadiza de innumerables experiencias reales y ficcionales. Desde esta perspectiva, la ambigüedad referencial de la narración fantástica no es otra cosa que la investidura temático-imaginaria de aquello que el escritor no puede desvelar, de aquello de lo que él mismo no puede hablar ("he cannot talk about...", al decir de Frye): de la literatura como arte del secreto.

Antes que en una nebulosa diferencia metafísica entre lo real y lo irreal, el secreto constitutivo de la ficción consiste en la brecha que la escritura literaria abre entre querer-decir y no-poder-decir. Querer-decir equivale a referir o significar algo, cae pues bajo el dominio de la significación como voluntad consciente, designación y denotación de entidades reales e ideales, siendo así que recubre por igual los conceptos de intención e intensión $\mathrm{y}$, en consecuencia, pertenece centralmente al orden conceptual que la semiología administra en cuanto tiene de semio-arquía, disciplina omnímoda que gobierna y garantiza la armonía preestablecida del mundo como si de un vasto sistema de signos naturales e intencionales se tratara. No-poderdecir, en cambio, es ahora la fórmula negativa que señala la apertura poética del lenguaje a su desconocida potencialidad significante, a la pura efectividad an-árquica de lo significable y lo decible más allá de las voliciones y las intenciones de un sujeto soberano, de todo significado sistemático y de todo referente ontológicamente custodiado, más allá incluso de todo aquello que la lógica, la gramática y la semiología dictaminan absurdo, sin sentido o, en suma, imposible. Decía Gérard Genette -a propósito de la teoría barthesiana de la escritura- que la obra literaria se constituye «en un monumento de reticencia y de ambigüedad", en un discurso trabajado por "una retórica del silencio", habida cuenta de que hace del lenguaje, instrumento al servicio del sentido común y del saber establecido, "un lugar de incerteza e interrogación» (L'envers des signes»; Genette, 1966). "Perdón por no querer decir...", la frase siempre entrecomillada, siempre entrecortada y como fuera de lugar que según Jacques Derrida inscribe la divisa de la literatura en tanto que arte del secreto ("La littérature au sécret»; Derrida, 1999), podría encontrar su contrapaso exacto en esta otra: "Perdón por no poder decir...". Si el discurso reticente, discurso de la no-dicción, permite sugerir la existencia de un secreto sin revelar en qué consiste, de forma que tal in-dicción presupone una tácita inducción al suspense o la suspicacia o la sospecha, la figura maestra de la ficción literaria emerge personificada en una voz que, reticente e irónica, finge no querer decir algo que, en el fondo, no puede decir. 
Imaginemos entonces la escena de reticencia en la que un escritor, preguntado por el secreto de su arte, se disculpa por no querer decir lo que puede o -lo que viene a ser lo mismo- por no poder decir lo que quiere. Se trata de la escena que encontramos en algunas narraciones de Henry James, especialmente en "The Figure in the Carpet» (1896), uno de sus más conocidos y celebrados cuentos sobre escritores (literary tales), cuyo motivo principal reaparecerá tiempo después, camuflado mas al fin reconocible, en esa pequeña obra maestra que es "The Beast in the Jungle» (1903). No por azar la sintaxis de ambos títulos, de idéntica estructura locativa, señala la ubicación de algo en un espacio que es al mismo tiempo continente y lugar de encubrimiento de un contenido. «La figura en la alfombra" y "La bestia en la jungla» dan noticia de un secreto (no importa de momento si literario $o$ vital) que pone en jaque a los personajes del relato y al propio lector en tanto que colaborador necesario en el desenvolvimiento de la trama. En los dos textos el nudo argumental queda atado por medio de una escena que combina tres factores: la contingencia que precipita un encuentro casual entre dos desconocidos; la confidencia inesperada que uno le hace al otro en el curso de un diálogo; y la reticencia que -bajo el signo de la preterición, la alusión, la elipsis o la ironía- impide que el secreto sea de veras revelado, bien porque el personaje no quiere decir lo que sabe, o porque no sabe en realidad lo que quiere decir. Veamos un poco más de cerca cuáles son los enredos argumentales que anudan esas dos escenas.

En primer lugar, «La figura en la alfombra» y su secreto irónico-literario. El relato parte de una situación que no deja de ser literariamente anecdóti$\mathrm{ca}$, por no decir trivial, pues se trata de un joven periodista literario encargado por delegación de un colega y amigo, George Corvick, de pergeñar una reseña sobre la última obra del famoso novelista Hugh Vereker, a quien el aprendiz de escritor pronto tendrá ocasión de conocer en persona y con quien podrá conversar a solas sobre los aciertos y defectos del artículo recién publicado y acerca de otras cuestiones de más largo alcance artístico y existencial. El narrador y protagonista, de nombre desconocido, instigado por una confesión ocasional del conspicuo escritor, según la cual hay en sus novelas un secreto artificio de extrema sutileza común a todas ellas, no solo emprende la tarea de averiguar en qué consiste esa clave única que permitiría comprender de golpe la obra completa de Vereker, sino que además comparte ávido su secreto con Corvick, y este hace lo propio con su amiga y finalmente esposa Gwendolen Erme, de manera que los tres se afanan por descubrir el enigma y miden entre sí sus dotes de perspicacia 
interpretativa, al tiempo que van estrechando ciertos lazos sentimentales con fortuna, por cierto, desigual.

"Figura en la alfombra" ("a complex figure in a Persian carpet", matiza no sin cierto exotismo un pasaje del texto) es solo una de las denominaciones que recibe el secreto involucrado en las novelas de Vereker. Hay muchos otros nombres, acumulados sobre todo en el capítulo tercero, donde tiene lugar la escena central de reticencia, donde el astuto novelista, en un alarde de disimulación autoirónica, parece jugar todo el rato al escamoteo verbal con el joven e incauto crítico. El discurso reticente se dispersa en una especie de polinimia que, lejos de contribuir a la determinación de lo mentado, insiste en acentuar la innombrabilidad del secreto. De tal forma que este puede ser también «un pequeño detalle" (a little point), "la cosa particular" (the particular thing), "un pequeño truco" (a little trick), "una astucia técnica" (a technical tip) o "un esquema exquisito" (an exquisite sche$m e)$; puede aparecer -con gesto bastante más egocéntrico- como «mi intención", "mi juego", "mi diversión" o "mi secretito" (my intention, my game, my sport, my little secret); o puede en fin mostrarse más solemne y metafórico a través de enunciados del tipo "ese misterio» (that mystery), «un tesoro enterrado" (a buried treasure), "un secreto a su pesar" (a secret in spite of itself) o «la verdadera cuerda (the very string) que ensarta todas mis perlas». Estas expresiones no son tanto signos del secreto como tal, sino de la reticencia misma con la que Vereker espolea inmisericorde la curiosidad del crítico y, por ende, la cada vez más atónita expectación del lector. De entre todas ellas importa destacar una: a little trick, un pequeño truco. La figura en la alfombra podría no ser más que un ardid, mera artimaña ilusionista, y el gran Vereker, caracterizado desde el principio por el narrador como un tipo tremendamente listo o ingenioso (awfully clever), podría no ser más que un retorcido bromista o un embaucador. De hecho, el ilustre literato pone en juego ciertas suposiciones capciosas cuando sugiere que el matrimonio de Corvick y Erme quizá les sea de ayuda para encontrar el secreto de su obra, aunque llega a decir poco después que una mujer nunca podrá averiguarlo. El relato insinúa, si es que no impone, cierta velada analogía entre el descubrimiento del secreto literario y la iniciación a la intimidad amorosa (conyugal y/o sexual), como si el enigma se redujera a una fábula entre alegórica y satírica de índole novelesco-erótico-detectivesca. George y Gwendolen logran supuestamente conocer el secreto por haberse casado o hallarse en trance de hacerlo, mientras que el narrador, soltero y decepcionado, jamás llegará a descubrir la solución del enigma. Corvick muere en un accidente, no sin antes haber compartido su pretendido descubrimiento del secreto con Gwendolen, que ya viuda publica una segunda novela -acaso influida, piensa el narrador, por el desciframiento del «enigma 
de Verekern-; se casa de nuevo con otro crítico literario, Drayton Deane, y fallece de parto prematuramente sin desvelar a nadie el secreto en cuestión. El truco o la broma estaría, con todo, más allá de cualquier presumible intención burlona, habida cuenta de que el conocimiento del secreto parece fatídicamente encadenado a la eventualidad real de una confidencia -al principio reticente- cuyo silenciamiento prefigura y produce otros silencios más lúgubres y definitivos: las muertes de Vereker, Corvick y Erme se irán sucediendo sin otra aparente coincidencia para el desesperado narrador que el hecho de que los tres se llevan el secreto a la tumba.

En segundo lugar, "La bestia en la jungla» y su secreto irónico-existencial. La nouvelle se inicia con el segundo encuentro -tan casual como el primero- entre John Marcher y May Bartram. Él no se acuerda muy bien de ella, ni de dónde se habían visto antes («no en Roma, sino en Nápoles»), ni de cuánto tiempo hacía ("no hacía siete años, sino casi diez»), ni siquiera de qué hablaron, de manera que será ella quien le recuerde las circunstancias precisas y ciertos pormenores de aquella primera vez, cuando Marcher le confió de improviso, durante una conversación que prometía ser superficial, el secreto que sobre sí mismo había guardado desde niño, el oscuro presentimiento de que «algo raro y extraordinario, posiblemente prodigioso y terrible» le reservaba el destino, un acontecimiento aún por venir que marcaría de forma indeleble su vida. May es la única persona en el mundo que sabe algo del secreto de John, y este, aunque había olvidado incomprensiblemente aquella confesión hecha tiempo atrás a una extraña, siente ahora alivio por haber compartido su idea fija y poder en adelante sobrellevar el peso de la angustia que su premonición le infunde acompañado de alguien que ha mantenido en secreto durante tantos años una confidencia semejante. Sucede así que ambos acuerdan «vigilar» juntos aquello y sellan un pacto que durará de por vida. El relato tiene algo de tragicomedia de errores: Marcher se obstina en reducir su vida entera a la expectativa (medio deseada, medio aborrecida) de un acontecimiento extraordinario y decisivo que termina por suceder sin que él mismo se dé cuenta; como tampoco se percata de que May no solo comparte su secreto, sino que además tiene que ver esencialmente con él, toda vez que el presentimiento de John, como ella misma sospecha desde el principio, apunta hacia «el sentimiento de peligro que crea la presencia del amor». Al personaje se le escapa que el secreto de su soledad estriba en que no está solo en absoluto. No lo está, porque compartir un secreto supone de inmediato la apertura de un reducto de intimidad del que únicamente son copartícipes quienes se han apartado o separado (se-cernere) de todos los demás al comunicarse aquello que, guardado fielmente en silencio, los mantiene unidos y al mismo tiempo alejados en sus respectivas soledades. 
"Bestia en la jungla» es la fórmula paródico-aventurera que James repite en distintos pasajes de la narración para describir el peligro vital o la amenaza que acecha en la oscuridad del presunto acontecimiento por venir. El secreto tiene también en este caso muchos nombres, entre los que se cuenta al menos uno ya presente en "La figura en la alfombra»: «el tesoro enterrado" (the buried treasure), sintagma que abunda tópicamente en las nociones de profundidad y encubrimiento, al lado de otras variantes como "la cosa más profunda dentro de ti" (the deepest thing within you) o "el abismo" (the abyss), y que alterna con una serie de expresiones alusivas a lo vago e indefinido: "algo" (something), "la cosa" (the thing), "la verdad real" (the real truth), "la gran vaguedad" (the great vagueness), "la aprensión que me obsesiona" (the apprehension that haunts me). John Marcher es un hombre hechizado, poseído por fantasmas, a haunted man, y su secreto hace de él un vacuo espectro del cuidado o la cura, un maníaco del presentimiento angustioso que Heidegger llamará más tarde die Sorge. Desde el comienzo mismo del relato la reticencia se propaga de una escena a otra, el silencio se va haciendo más denso, más opaco, y resuena con más fuerza y misterio en las palabras cómplices de May, que termina siendo la verdadera depositaria del secreto de John, su único testigo, y es capaz al final de acercarse a él íntimamente, casi como una amante, "como si aún cargara con lo no dicho (the unspoken)" y «su movimiento quisiera acentuar de manera sutil lo que a la vez decía y se negaba a decir». ¿Qué quiere decir eso no dicho que comparten como una extraña profecía autocumplida los dos personajes a lo largo de esta historia? ¿Que Marcher es incapaz de amar, que no puede amar a May Bartram, precisamente a la mujer que le ha amado, cuidado y protegido toda su vida, o tal vez que su capacidad de amar se ha retraído en sí hasta casi abismarse enfermizamente en el fondo egocéntrico de su vacía intimidad?

No han faltado intérpretes para quienes el secreto no quiere decir otra cosa que la homosexualidad reprimida de Marcher/James, o sea: que la reticencia significa "the thing", la cosa ambigua o indefinida que la figura de la preterición estaría delatando de forma tanto más elocuente cuanto más silenciosa, pues de lo que se trataría es de querer decir precisamente lo que no se debe querer ni se debe decir en modo alguno, esa cosa nefanda $y$ bestial sobre la que pesan como una losa funeraria el tabú y el eufemismo. «Unspeakable, Unmentionable, nefandam libidinem», ha comentado al respecto Eve Kosofsky Sedgwick (1990, 200 y ss.), que hace notar además la sintomática ocurrencia -demasiado obvia, más bien, o demasiado equívoca- de la palabra queer en varios pasajes del relato: «Él no molestaba a los demás con la rareza (the queerness) de tener que conocer a un hombre hechizado (a haunted man), aunque había tenido momentos de especial 
tentación al escuchar a otros decir que estaban «descolocados» (unsettled)». O bien: «Por supuesto, el resto del mundo le creía raro (queer), pero ella, sólo ella sabía en qué medida y por qué era raro, lo cual la capacitaba precisamente para disponer los velos en su justa doblez. Ella aceptaba su alegría (gaiety) - pues tenía que hacerla pasar por alegría- como aceptaba todo lo demás». En una nota de los cuadernos (Lamb House, 27 de agosto de 1901) James propone una lectura bien diferente de esta historia. Lo que tenía que pasar -y pasa: inadvertido para el personaje- es «que nada ha pasado" ("that nothing has happened"). May ha amado a John siempre, y este amor devoto y reservado era justo aquello que a él también podría haberle sucedido. "Pero es demasiado tarde - ella ha muerto", y él solo alcanza a comprender todo lo que ella ha significado ("all she has meant") tras haberla perdido. La significación, meaning, llega demasiado tarde, too late, cuando ya se ha producido la pérdida, cuando lo que pudo haber sido y no fue se convierte en una especie de cenotafio, lugar señalado de una ausencia, signo espectral de casi nada, pues solo significa que ha sucedido (¿precisamente?) el no suceder nada.

El presente desde el que se enuncia el relato es por fuerza anacrónico, viene siempre "demasiado tarde» con respecto a lo relatado, como las interpretaciones que de la narración puedan seguirse, y el idioma plural de la ficción, ambiguo y reticente, no se agota en ninguna estratagema encubridora, en la tarea sibilina, por ejemplo, de querer decir lo que no se puede o no se debe decir bajo ningún concepto (de conformidad con los conceptos represivos o normativos de la gramática, la estética y la moral), antes bien muestra, inagotablemente, la falla que la literatura abre entre el quererdecir en general y el no-poder-decir en absoluto. Así como la intención de quien escribe jamás queda del todo reabsorbida en la intensión del texto, así tampoco puede la intensión satisfacer total e inequívocamente la posible intención del autor o del lector. El problema interpretativo que pone de manifiesto el secreto de Marcher concierne menos a la determinación de un significado intencional (reprimido y enterrado, pero siempre policialmente delatable a través de algún método) que a la irrupción en el relato de una falla entre la vida real y el sentido. Reparemos en las conclusiones con las que se cierra el capítulo tercero de La bestia en la jungla:

¿Qué significaba todo aquello?; es decir, ¿qué significaba ella y su vana espera y su probable muerte y la insondable admonición de todo eso, a no ser que, a estas alturas de la vida, fuera ya simple y abrumadoramente demasiado tarde? En ninguna fase de su raro estado de conciencia había admitido nunca el susurro de tal correctivo; hasta estos últimos meses, jamás había sido tan infiel a su convicción como para no sostener que lo que iba a sucederle tenía su tiempo, tanto si le parecía que lo tenía como 
si no. Lo que, por fin, por fin, ciertamente no lo tenía, o si lo tenía era en una medida muy menor, llegó a ser, muy pronto y según le iban pasando cosas, una inferencia con la que su vieja obsesión tuvo que contar: la apariencia, cada vez más confirmada, de que a la gran vaguedad que arrojaba la larga sombra en la que había vivido no le quedaba apenas ningún margen. Puesto que debía haberse encontrado con su destino en el Tiempo, también su destino tenía que haber actuado en el Tiempo; y mientras despertaba a la sensación de no ser ya joven, que era exactamente la sensación de ser viejo, y a la vez, también a la sensación de ser débil, despertó además a otro asunto. Todo estaba ligado; él mismo y la gran incertidumbre estaban sujetos a una ley igual e indivisible. Cuando las posibilidades mismas se habían vuelto consecuentemente viejas, cuando el secreto de los dioses había languidecido, y hasta tal vez se había evaporado, aquello, y sólo aquello, era el fracaso. No hubiera sido fracaso estar arruinado, deshonrado, puesto en la picota o ahorcado; el fracaso era no ser nada. Y así, en el oscuro valle hacia el que su camino le había conducido dando un giro imprevisto, se sentía no poco desconcertado y como a tientas. No le preocupaba qué golpe tremendo podría acecharle, con qué ignominia, con qué monstruosidad pudiera ser aún asociado -puesto que, después de todo, no era tan anciano como para no poder sufrir-, si tan sólo fuera decentemente proporcional a la postura mantenida toda su vida ante la ominosa presencia de aquello. No tenía sino un deseo: no haber sido "estafado".

Este largo pasaje da sin duda una idea perspicua del concienzudo estilo introspectivo que distingue a las narraciones jamesianas. Pero muestra sobre todo el colapso obsesivo de una conciencia enfrentada a su propia tergiversación. "La bestia en la jungla» y "La figura en la alfombra" cuentan la doble historia de una interpretación fallida. El fallo interpretativo arrastra sin remedio en ambos relatos al fracaso vital, the failure, más trágico y, desde luego, fulminante en el caso de John Marcher, más cómico y al parecer intranscendente en el del joven crítico que busca sin éxito el tesoro enterrado en la obra de Vereker. En esta recíproca correspondencia entre fallo interpretativo y fracaso vital se concreta la ejemplaridad teórico-literaria que la crítica ha creído hallar a menudo en algunas de las narraciones breves de James. Así, Wolfgang Iser abría El acto de leer (1976) con unas cuantas observaciones hermenéuticas sobre "La figura en la alfombra» justificadas por el hecho notorio de que «el propio James convierte en sujet literario la relación entre obra e interpretación». Que el sentido del relato, como quiere Iser, tenga carácter figurativo y, por tanto, solo se deje captar como imagen, que la imagen se sustraiga a la dimensión referencial del texto y sea irreductible a una explicación discursiva, basada en la rígida escisión sujeto/objeto, supone que la figura en la alfombra "ya no es explicable, sino sólo experimentable como efecto" suscitado en parte por el texto y en parte producido al albur 
de cada acto de lectura. Otros intérpretes han abundado, antes y después, en argumentos similares o reconducibles a las tesis de Iser, destacando -a modo de condición pragmática de toda lectura feliz- la sensibilidad afectiva y la penetrante inteligencia de Corvick frente al frígido y un tanto miope intelectualismo del narrador (Levy, 1962); defendiendo el abierto rechazo jamesiano de la interpretación como actividad abstracta e intelectual y aduciendo a título de prueba la analogía -propiciada por el relato- entre la intimidad erótica que une a George y Gwendolen y la interacción texto-lector (Salmon, 1980); o detectando en los secretos de Vereker y Marcher cierta influencia del pragmatismo y la semiótica de Charles S. Peirce sobre el realismo experimental de su amigo Henry James (Lindholt, 1988). De suerte que si la figura en la alfombra tiene que ver en lo esencial con la producción de sentido (semiosis) en tanto que proceso dinámico e interminable, ha de fracasar por fuerza cualquier interpretación fundada en "one-to-one association of text and meaning (Liss, 1995). Esta posible relación entre Peirce y James resulta particularmente oportuna, dado que enfatiza la centralidad que el problema de la interpretación fallida adquiere también en "La bestia en la jungla». No es ya que el protagonista del relato pueda representar un trasunto caricaturesco del propio Peirce, según conjeturan algunos críticos basándose en las consabidas premisas biográficas, sino que el secreto de Marcher no se distinguiría finalmente de esa "gran vaguedad (the great vagueness) que arrojaba la larga sombra en la que había vivido». Es de suponer que para el filósofo de la semiótica el secreto del personaje de James habría sido tan solo un espejismo mental, el efecto nocivo de una vaguedad ligada de raíz a la incertidumbre y la indeterminación de ciertos hábitos lingüísticos (Quigley, 2007). Efecto pues de «alguna vaga sombra de una idea", como deplora Peirce irónicamente en un curioso fragmento de «How to Make Our Ideas Clear» (1878) que parece retratar el sórdido destino de John Marcher:

Hay muchos hombres que durante años han acariciado como su afición favorita alguna vaga sombra de una idea, demasiado insignificante para ser positivamente falsa [some vague shadow of an idea, too meaningless to be positively false], y que, si embargo, la han amado apasionadamente, la han hecho su compañera día y noche y, entregándole energía y vida, han abandonado por ella todas sus ocupaciones, viviendo en suma con ella y para ella hasta convertirse en carne de su carne y sangre de su sangre, hasta que, de repente, despiertan una brillante mañana y descubren que se ha ido, que se ha evaporado limpiamente, como la bella Melusina de la fábula, y con ella la esencia de su vida.

No hay ficción sin vaguedad, como no existe lenguaje sin algún grado de intrínseca incerteza. En sus dos relatos James tematiza hiperbólicamente la falibilidad de la interpretación, entendiendo por tal el hecho de que el 
lenguaje mismo crea la falla entre los proyectos de sentido y las situaciones prácticas o vitales a las que dichos proyectos se aplican. Como la vida humana, el texto literario está sujeto a la falibilidad, nunca está determinado unívocamente, engendra relaciones impredecibles, se presta a infinidad de desarrollos erráticos, azarosos, titubeantes, improvisados. Como sucede tantas veces con el texto literario, la vida humana deviene al fin y al cabo una especie de cuento ilegible. No hay en todo ello doctrina: tan solo constatación de lo evidente. En un lúcido ensayo sobre «La figura en la alfombra", Hillis Miller señalaba que el relato jamesiano ofrece una figuración de la «ilegibilidad" (unreadability) inherente al lenguaje de la obra literaria. Lo ilegible no se sigue sin más de la ambigüedad o la plurisignificación de las palabras, sino que resulta de la presencia textual de dos o más sentidos contradictorios, incompatibles pero mutuamente co-implicados. "La ilegibilidad es la generación por el texto mismo de un deseo de posesión del logos, mientras al mismo tiempo el texto frustra ese deseo, en una torsión de indecibilidad que es inmanente al lenguaje” (Hillis Miller 1980, 113). Cierto es que la experiencia más elemental impone la colisión de nuestras presunciones de sentido con la terca insignificancia que parece ostentar el acaecer estrictamente real. Más aún: toda experiencia vital lleva consigo una expectativa de sentido que la propia experiencia en curso termina casi siempre por decepcionar. "¿Qué significaba todo aquello?», se preguntaba el malhadado personaje de "La bestia en la jungla», valiéndose de una fórmula que podría haber utilizado quizá con más razón -al menos hermenéuticael joven crítico literario de "La figura en la alfombra». James explota narrativamente la tendencia ordinaria a someter la vida real a los interrogantes que plantearía un texto cuyo tenor literal causara desconcierto y ofuscación en el lector. En muchas de sus ficciones de asunto literario la interpretación forma parte de la intriga no solo en el sentido especular de que la interpretación dentro del relato moviliza la trama argumental y desencadena hasta cierto punto la interpretación del lector fuera del relato, sino también en la medida en que configura la ecuación entre fallo interpretativo y fracaso vital. ¿Dónde está el fallo?

3.

En concebir el secreto como mero significado intencional, meaning, sentido críptico susceptible de esclarecimiento, y no como una ejecución dinámica y a cada paso tentativa, performance en ciernes de una intriga, entre cuyos factores desempeña una función crucial el proceso interpretativo llevado a cabo dentro y fuera del texto. John Marcher teme haber 
sido "estafado» (o "vendido", sold) y el joven crítico sospecha que «el tesoro enterrado" de Vereker acaso no sea sino un "mal chiste", a bad joke. Los dos personajes resultan estafados, desde luego, pero solo por su propio acto de misreading. El secreto está en el truco, en efecto, pero el truco no consiste sino en la manera de ejecución de la intriga («his manner is his secret...»), y el peculiar diseño constructivo de la intriga hace del relato de James una ficción-trickster. Recordemos que la palabra "intriga" viene en nuestra lengua del italiano intrigare, y esta del latín intricare -de donde eintrincar»: 'liar', 'embrollar'-, que deriva del verbo tricari -'enredar', 'complicar', 'engañar'-, formado a partir de tricae, 'impedimentos' o 'embarazos' (término, este último, procedente del portugués o tal vez del astur-leonés baraço, 'cinta' o 'lazo', muy probablemente tomado a su vez del sustantivo español por el francés embarras, y de este trasladado al inglés embarrassment: Embarrassments es -feliz coincidencia- el título dado por James al libro de narraciones que recoge por vez primera "The Figure in the Carpet»). De la misma raíz latina provienen en francés tricher, 'engañar' o 'embaucar', y en inglés trick, 'truco', y trickster, 'burlón', 'pícaro', 'truhán'. Luego el secreto del relato no está sino en el enredo o el embrollo de la intriga trucada por un intrigante socarrón, el trickster. Es sabido que la figura del trickster, el pícaro divino, suele aparecer bajo forma animal, humana o numinosa en el folclore de los pueblos más diversos desde las épocas más remotas, y alcanza en el dios Hermes su expresión mitológica suprema. Para Jung el motivo del trickster, lejos de limitarse al imaginario mítico, surge también de modo espontáneo e insospechado en las formas de vida civilizada siempre que el individuo «se ve expuesto a contingencias que aparentemente obstaculizan, con un propósito deliberado y maligno, su propio quehacer. Entonces suele hablar de "duendes" y de "caprichos del destino" (Jung 2002, 246). Tratemos de recapitular algunos caracteres de la ficción-trickster tal como se presenta en los relatos de James:

1. La ficción-trickster gira siempre en torno a un secreto, un enigma o un ardid y, por eso mismo, puede definirse también como una variedad de ficción hermética en la que una incógnita interpretativa da lugar a una intriga cuyo sentido último queda en el aire o resulta en cierto modo ilegible. El relato pretexta la búsqueda de la solución, pero el nudo argumental (la desis aristotélica) no alcanza el desenlace (lysis), de manera que la ficción se cierra sobre su propia enigmaticidad manteniendo en suspenso el motivo central de la trama. La narración como pesquisa, busca, quête destinada al fracaso, pues el secreto o el enigma hace las veces de motor de las acciones, promete el hallazgo de una clave resolutoria y, sin embargo, parece encubrir al mismo tiempo nada más que un pequeño truco (a little trick), una treta o una broma. Es característico de la ficción-trickster que 
el desenlace no sea otro que la imposibilidad de desenlazar el nudo, de zanjar la disyuntiva entre la simple naturaleza retórico-literaria del truco o la efectiva consistencia real del secreto. Diferir o retardar el desenlace suele ser indispensable en todo relato de misterio, pero en la ficción-trickster la estrategia dilatoria nunca logra un final concluyente ni favorece una descarga catártica de las expectativas por medio de la agnición o del desvelamiento de un sentido oculto. La spes hermeneutica (según expresión de Frank Kermode), defraudada, va a dar en una exacerbación de lo que podríamos llamar la angustia hermenéutica, acrecentada además por el double bind que pone en primer plano el texto. El lector de los relatos de James quizá pueda sentirse finalmente "estafado", lo mismo que los personajes de "La figura en la alfombra" y "La bestia en la jungla», pero es harto probable que el desengaño último se deba sobre todo a sus propios hábitos interpretativos, puestos ciertamente en crisis por las estratagemas ilusionistas de la ficción-trickster. En The Genesis of Secrecy (1979), Kermode ha estudiado hasta qué punto la creencia de que los textos sagrados pueden contener la clara proclamación de un mensaje ha coexistido con la convicción de que son un receptáculo de secretos y en qué medida el canon literario secular ha heredado a su modo esta ambivalencia transmitida atávicamente por los textos sagrados. Si toda narrativa presupone y cultiva la idea de que hay, entrañado en el texto, un secreto por descubrir, o un sentido críptico que interpretar correctamente (Benjamin, 2013), la ficción-trickster cuestiona paródicamente dicha idea y lanza sobre ella la sospecha torvamente nietzscheana de si el gato encerrado en toda interpretación no será otro que la furtiva implicación del intérprete en el fraude universal. El mundo y el libro, concluye melancólico Kermode (1979: 145), «son irremediablemente plurales, infinitamente decepcionantes; estamos solos frente a ellos, conscientes de su arbitrariedad e impenetrabilidad, sabiendo que pueden ser narraciones sólo por nuestras impúdicas intervenciones, y susceptibles de interpretación sólo por nuestros trucos hermenéuticos (by our hermeneutic tricks)》.

2. En la ficción-trickster el motivo principal -la incógnita o la confusión- depende enteramente, según hemos visto, de la malinterpretación de un texto o de un hecho acaecida en el interior del mundo de ficción y transferida ipso facto, en tanto que requisito hermenéutico, al acto de lectura. En "La figura en la alfombra" asistimos a la proliferación e imbricación de múltiples textos, por lo general solo mencionados o aludidos: la última novela de Vereker; la reseña del narrador; la nota enviada a este por el insigne novelista tras haberle inducido a barruntar la presencia de un secreto en su obra; las cartas entre el narrador, Gwendolen y George; el ensayo crítico inacabado de Corvick; la segunda novela de Erme, y, en fin, 
la conversación con Drayton Deane, en la que el narrador le refiere, palabra por palabra, cuanto él mismo escribirá poco después en el relato que leemos, componen un abigarrado simulacro meta- e intertextual que, aun siendo en apariencia decisivo para la comprensión del texto, se hurta total o parcialmente a cualquier posibilidad de acceso directo y comprobación. En "La bestia en la jungla» los diálogos entre John Marcher y May Bartram, ejercicios admirables de prestidigitación verbal, van trazando una especie de exégesis evanescente de aquello que, desconocido y por venir, se sobrentiende indecible y solo existe en forma de juegos de palabras alusivas y elusivas. El lector intrigado se vuelve cómplice necesario de un narrador hermético-intrigante. Es frecuente que uno de los personajes, identificado a veces con la vOz narrativa principal, asuma la figura escurridiza del intrigante, pero el imbroglione que urde la trama ha de contar siempre con la connivencia propiciatoria de otro, el intrigado, cuyo correlato más allá del texto se sitúa invariablemente en la figura del lector. La ficción-trickster supone al menos dos perspectivas en contraste, de las que se torna evidente su condición errática y falible. El perspectivismo contrariado y problemático es imprescindible para provocar el efecto de ambivalencia: ¿estamos ante un secreto o más bien frente a un mero engaño? Vale responder genéricamente invocando aquel vitriólico adagio de Nietzsche que reza: «Y si somos engañados, ¿no somos por eso también engañadores?, ¿no nos es inevitable ser también engañadores?» (Humano, demasiado bumano, Prefacio, 3). Trickster no es, en rigor, ninguno de los personajes, por sagaz e ingenioso que pueda resultar (como es el caso de Henry Saint-George en "The Lesson of the Master»), sino la propia intrincación de puntos de vista, opiniones e insinuaciones a partir de los discursos del narrador, los personajes $y$ el lector. De modo que en la ficción-trickster la intriga se resuelve, paradójicamente, en la insolubilidad de su anudamiento, y la interpretabilidad última de la historia pasa por la confirmación de la indecidibilidad de su sentido.

3. En la ficción-trickster la indecidibilidad del sentido presupone inevitablemente las duplicidades y las ambigüedades (real-imaginario, cotidiano-extraordinario, verosímil-maravilloso, etc.) que se han venido atribuyendo a los mundos posibles de la literatura fantástica. La ambigüedad ha sido de hecho la propiedad que, desde Edmund Wilson ("The Ambiguity of Henry James", 1934) hasta Slomith Rimmon (The Concept of Ambiguity, 1977) y Christine Brooke-Rose (The Rhetoric of Unreal, 1981), se ha asignado a la narrativa de Henry James en tanto que exponente consumado de la ficción fantástica posromántica. La conocida teoría de Todorov, según la cual lo fantástico depende esencialmente de una vacilación del lector respecto de la naturaleza (empírica $v s$. imaginaria, natural $v s$. sobrenatural) 
de un acontecimiento extraño, se funda también en la retórica de lo ambiguo y en su eficacia narrativa, aunque adolece de excesivo psicologismo y de un racionalismo más bien estrecho. Ernst Jentsch fue quien, en un artículo de 1906 titulado "Zur Psychologie des Unheimlichen", caracterizó lo siniestro a través de las nociones de incertidumbre (Ungewissheit) e inseguridad (Unsicherheit), precisamente ejemplificadas por los cuentos de E. T. A. Hoffmann, que Freud retomará después como punto de partida y modelo de su ensayo Das Unheimliche (1919). El efecto siniestro, advertía Jentsch, tiene lugar cuando se deja al lector en la incerteza de "si en una determinada figura tiene ante sí a una persona o a un autómata». Es decir, lo siniestro implica, en grados ciertamente muy variables, la ambivalencia fundada en el dualismo categorial que distingue la vida orgánica de la artificial, la naturaleza de la técnica, lo espontáneo de lo calculado e intencional. La misma duda puede suscitar, llegado el momento, cualquier suceso o curso de acontecimientos: ¿es espontáneo e inintencionado o está quizá dictado por algún pérfido designio en la sombra? La interpretación natural coordina habitualmente series de hechos con series de causas (o de antecedentes-consecuentes), pero cuando una casualidad demasiado significativa induce a presagiar la intromisión subrepticia de una causalidad anómica e irracional, entonces la interpretación tiende a sospechar la presencia celada de una serie de intenciones subjetivas o demónicas. Próxima al relato fantástico, o cuando menos deudora de algunos de sus procedimientos característicos, la ficción-trickster pertenece a las variedades del realismo cuasi-sobrenatural, es decir, a una modalidad de mímesis narrativa en la cual la tematización de la realidad fenoménica considerada objetiva no puede ser netamente discriminada de las manifestaciones fantasmagóricas del pensamiento, el sueño y la imaginación. La obra de James se inscribe pues en una tradición heterogénea de realismo psicofánico que se inicia con Hawthorne, Poe, Maupassant o Nerval y llega a Kafka, Conrad, Borges o Cortázar.

4. En la ficción-trickster predominan los argumentos novelescos de base anecdótica sobre confusiones, fraudes, burlas y ardides. El enredo parte de una situación vital más o menos realista y cotidiana, sobre cuyo trasfondo anodino se perfila el fuerte contraste entre la estupidez o simpleza de un personaje y la agudeza e ingeniosidad del trickster (estereotipos del simple, el tunante, el bribón, el pícaro...). El nudo argumental suele consistir en el embrollo cómico a que da lugar «entender algo demasiado literalmente", "buscar sentidos ocultos donde no los hay", o cualquier clase de sospecha excesiva y hasta paranoide. Genéticamente, la ficción-trickster tiene su ascendiente primitivo en el acervo proverbial, humorístico y anecdótico de la tradición folclórica, que evidencia una predilección por 
el contraste paradójico y el absurdo en fórmulas como refranes, chistes y adivinanzas (Meletinskij 2014, 29-37). De ahí la afinidad de tales ficciones con algunos procedimientos típicos de la novella: paralelismo, desdoblamiento e inversión de nombres, personajes, situaciones y acciones. El tema del doble es, por ejemplo, recreado magistralmente por James en el relato "The Jolly Corner», donde Spencer Brydon regresa al viejo caserón abandonado de su infancia y juega allí al escondite con el álter ego espectral de un pasado que él mismo jamás llegó a vivir. El motivo de la inversión fantasmagórica de papeles protagoniza "The Private Life», donde Lord Mellifont solo está realmente presente en sus vacuas y brillantes puestas en escena públicas, mientras que el auténtico Clare Vawdrey únicamente existe cuando encomienda a su sosias comparecer en sociedad y se retira del mundo para entregarse a la escritura de sus obras. Diversos paralelismos entre relación amorosa y escritura novelesca recorren no pocos de los literary tales de James, cuyas ficciones breves dan además otra vuelta de tuerca a los recursos de la novela de misterio y de fantasmas con el fin de encontrar espacios de invención menos frecuentados y acaso más fascinantes. "La única obligación que podemos exigir de antemano a una novela, sin incurrir en la acusación de ser arbitrarios, es que sea interesante», leemos en "The Art of the Fiction». No es difícil adivinar algunas de las razones de orden práctico que podían mover a un escritor fin de siècle (y de éxito más bien precario) como Henry James a erigir lo interesante en cualidad inexcusable de la narrativa. ¿Cómo despertar de nuevo el interés de los lectores de ficción después de las extraordinarias invenciones de Hawthorne, de Poe y de Dickens, después de Balzac y Flaubert, en tiempos de Maupassant y Turguéniev, de la novela gótica y las ghost stories? Como en la estética de los románticos, "lo interesante» califica en James el aspecto llamativo, extravagante y algo enrevesado de una intriga novelesca que deja entrever la manera de ejecución de su autor.

5. La ficción-trickster potencia la perceptibilidad de la ejecución narrativa, y en particular de la trama, cuyas acciones aparecen expresamente como efectos de una orquestación deliberada de casualidades significativas e intenciones ocultas. En el arranque de "The Aspern Papers", la historia que va a ser contada se nos presenta ya como resultado de un plan arteramente improvisado por los personajes: "Había puesto mi confianza en mistress Prest; en verdad, sin ella habría avanzado más bien poco, pues la única idea provechosa en todo aquel asunto surgió de sus labios amigos. Ella fue quien dio con el pequeño corte que soltó el nudo gordiano». Es habitual la narración en primera persona y, por ende, la explicitación de la enunciación narrativa y sus circunstancias, de tal forma que el proceso mismo de composición tiende a ser ficcionalizado, o cuando menos 
oblicuamente representado. James sentía fascinación por el relato como relato: en el prefacio a The Ambassadors afirma que «está la historia del héroe y, gracias a la íntima conexión de las cosas, la historia de la historia misma (the story of one's story itself)", y confiesa que este último embrollo (the latter imbroglio), la historia del proceso de escritura de una historia, le parece en ocasiones el más objetivo de los dos. Se da así cierta especularidad entre lo acontecido en el relato y el acontecer del relato como tal, planos que vienen a intrincarse en un solo y el mismo acto de ejecución narrativa. En "La figura en la alfombra" el relato que leemos reproduce $l i$ teralmente el relato oral del narrador a Drayton Deane sobre los extraños sucesos que ha tenido ocasión de vivir. El proceso narrativo se vuelve hacia sí en un movimiento de invaginación que simula una circularidad entre el interior y el exterior de la narración. Las ficciones de James postulan la ambigüedad ontológica no como una propiedad inherente a la realidad tout court, sino como el modo de ser crítico de nuestra experiencia de lo real en el lenguaje y a través del lenguaje. De la ficción-trickster cabe afirmar así lo que Irène Bessière ha afirmado del relato fantástico: «Para seducir tiene que defraudar», y su lenguaje no tiene existencia en sí mismo, sino que está como fuera de sí, ya que puede leerse como un trastorno de muchos otros discursos -literarios o no- que parasita y deconstruye «desde dentro de ellos mismos" (Bessière 1974, 11-14 y 35 y ss.).

La ficción-trickster no supone tanto la aparición de un modo nuevo y especial de narrativa, sino más bien la decantación reflexiva de procedimientos y estrategias que siempre han estado larvados en el arte del relato y la ficción. En James podemos encontrar el más perfecto equilibrio entre el placer que procura el espectáculo de la práctica del arte de narrar y el interés que cobra la teoría implícita en dicha práctica. Es más: sus narraciones contienen una variación caleidoscópica sobre la idea fija del perspectivismo ilimitado que para él encerraba "la casa de la ficción» ("Prefacio a The Portrait of a Lady). No se trata, claro está, de buscar una figura aún por descubrir en la alfombra jamesiana, pero sí de advertir que el tan traído y llevado secreto literario termina por confundirse con la propia elaboración de la obra. "Es mi vida", responde Gwendolen Erme a la pregunta final del narrador sobre lo que ella sabe del enigma de Vereker. Se ha hecho notar con frecuencia que la verdadera vida de James fue su obra literaria, y él mismo parecía estar plenamente convencido de ello, a juzgar por las declaraciones autobiográficas dispersas a través de los ensayos críticos, los prefacios a las novelas y los cuadernos de notas. Pero quien dedica su vida entera al oficio de narrar no puede escapar de las trampas que la ficción tiende a todo aquel que se aventura a explorar sus dominios. No puede, porque los trucos de la intriga afectan por igual al autor que cree 
manejarlos y al lector que cede a sus hechizos. En sus notas de trabajo James aparece una y otra vez como el intrigante intrigado, no solo absorto en las dudas constantes que le asaltan sobre el interés y las posibilidades narrativas de un tema, una anécdota o una donnée, sino enredado él mismo en la endiablada tejeduría de la intriga, sabiendo que debe tirar de alguno de los hilos, necesariamente, pero no de cuál tirar, ni cómo ni hasta dónde, pues hay tantas hebras y tan variadas que cada una podría anudarse con otras muchas de mil formas.

Al final vence el arte de narrar. Admitamos que el escritor de ficciones está condenado a fracasar como trickster para que la intriga pueda triunfar y el secreto truco del relato fascinar no menos al narrador que al lector. Siempre es demasiado tarde para que el autor revele el secreto de su arte, y lo que James no podía decir de su obra, in progress o una vez realizada, viene a confundirse con esa "gran vaguedad" que trató de despejar en la escritura, quizá con ese "no ser nada" o "no suceder nada" que para el personaje de Marcher constituía el mayor de los fracasos. "QQué hay en la idea de Demasiado tarde?", "What is there in the Idea of Too Late?", escribe James en una nota muy comentada de sus cuadernos ( 5 de febrero de 1895) donde reflexiona sobre lo que pudo haber sido y no fue, pensamiento recurrente, poco menos que obsesivo a partir de su edad madura, y donde esboza algunos apuntes para relatos como «La bestia en la jungla». De entre tales apuntes hay uno sin duda precursor de la futura relación entre John Marcher y May Bartram que llama poderosamente la atención: "She is his Dead Self: he is alived in her and dead in himself: "Ella es su Identidad Muerta: él está vivo en ella y muerto en sí mismo». Fórmulas parecidas se despliegan en los cuentos de fantasmas de James, en sus sofisticadas e insólitas narraciones sobre dobles y en sus casi siempre malogradas historias de amor perversamente románticas. El prodigio tanto tiempo esperado por John no era otro que haber vivido en May sin darse cuenta y no haber sido él mismo más que en ella y a través de ella. No menos prodigiosa es la historia de aquel renombrado novelista que solo vivió de veras en su obra y solo en ella dejó cifrado para siempre el secreto de su arte.

\section{REFERENCIAS BIBLIOGRÁFICAS}

BARTHES, Roland. "Structure du fait divers». En Essais critiques. Paris: Seuil, 1964. Benjamin, Shoshana. «Is There a Single Right Interpretation for Cryptic Texts?». Poetics Today, 2013, vol. 34, n. ${ }^{\circ}$ 4, pp. 519-562.

BEssière, Irène. Le récit fantastique. La poétique de l'incertain. Paris: Larousse, 1974. 
Brooke-Rose, Christine. A Rhetoric of Unreal. Studies in Narrative E Structure, especially of the Fantastic. Cambridge, Mass.: Cambridge University Press, 1981. Ceserani, Remo. Il fantástico. Bologna: Il Mulino, 1996.

DERrIDA, Jacques. «La littérature au secret - Une filiation impossible». En Donner la mort. Paris: Galilée, 1999.

Frye, Northrop. Anatomy of Criticism. New Jersey: Princeton University Press, 1957. GenetTe, Gérard. "L'envers des signes». En Figures I. Paris: Seuil, 1966.

IsER, Wolfgang. Der Akt des Lesens. Theorie ästhetischer Wirkung. München: W. Fink, 1976.

JAMEs, Henry. The Figure in the Carpet and other stories. Editado por Frank Kermode. Harmondsworth: Penguin Classics, 1986.

James, Henry. The Complete Notebooks of Henry James. Editado por Leon Edel \& Lyall H. Powers. Oxford: Oxford University Press, 1987.

James, Henry. "The Beast in the Jungle» $\mathrm{y}$ "The Art of Fiction». En Tales of Henry James. A Norton Critical Edition. Editado por Christof Wegelin y Henry B. Wonham. New York \& London: Norton \& Company, 2003.

James, Henry. The Art of the Novel: Critical Prefaces. Editado por Richard P. Blackmur. Prólogo de Colm Tóibín. Chicago: Chicago University Press, 2011.

Jung, Carl Gustav. "Acerca de la psicología de la figura del trickster». En Los arquetipos y lo inconsciente colectivo. Obra Completa, vol. 9/1. Traducción de Carmen Gauger. Madrid: Trotta, 2002.

KERMODE, Frank. The Genesis of Secrecy. On the Interpretation of Narrative. Cambridge, Mass. \& London: Harvard University Press, 1979.

LEvy, Leo B. "A Reading of "The Figure in the Carpet" . American Literature. Duke University Press, 1962, vol. 33, n. ${ }^{\circ} 4$, pp. 457-465.

Lindholt, Paul J. "Pragmatism and "The Beast in the Jungle" . Studies in Short Fiction, 1988, vol. 25, n. ${ }^{\circ} 3$, pp. 275-288.

Liss, David. "The Fixation of Belief in "The Figure in the Carpet»: Henry James and Peircean Semiotics». Henry James Review, 1955, vol. 16, n. ${ }^{\circ}$ 1, pp. 36-37.

Meletinskij, Eleazar M. Istoricheskaja poètika novelly [Moskva, Nauka, 1990]. Poetica storica della novella. Traducido por Laura Sestri; editado por Massimo Bonafin. Macerata: Eum Edizioni, 2014.

Miller, Joseph Hillis. "The Figure in the Carpet». Poetics Today, 1980, vol. 1:3, pp. 107-118.

PeIrce, Charles S. "How to Make Our Ideas Clear». [Popular Science Monthly, January 1878, pp. 286-302]. “¿Cómo esclarecer nuestras ideas?». Traducido por José Vericat. En El hombre, un signo. El pragmatismo de Pierce. Barcelona: Crítica, 1988.

Quigley, Megan. "Beastly Vagueness in Charles S. Peirce and Henry James». Philosophy and Literature, 2007, vol. 31:2, pp. 362-377.

Rimmon, Slomith. The Concept of Ambiguity - The Example of James. Chicago: The University of Chicago Press, 1977.

SALMON, Rachel. "A Marriage of Opposites: Henry James's "The Figure in the Carpet» and the Problem of Ambiguity». English Literary History, 1980, vol. 47, pp. 788-803. 
SEDGWICK, Eve Kosofsky. Epistemology of the Closet. Berkeley-Los Angeles: California University Press, 1990.

Todorov, Tzvetan. Introduction à la littérature fantastique. Paris: Seuil, 1970.

Todorov, Tzvetan. "Le secret du récit». En Poétique de la prose. Paris: Seuil, 1971. 